\title{
Selected bone morphogenetic proteins - the possibility of their use in the diagnostics and therapy of severe asthma
}

The authors declare no financial disclosure

\begin{abstract}
Asthma is a chronic heterogeneous illness of the lower airway with an inflammatory basis, developing from hyperresponsiveness and bronchial obstruction. One of the more unfavourable processes occurring in the airway are the long-term changes of the respiratory tract known as remodelling, resulting in complete irreversible obstruction. Bone morphogenetic protein (BMP) is a member of the Transforming Growth Factor beta (TGF- $\beta$ ) superfamily, which regulates processes in embryonic and post-embryonic development. The role played by BMP is regulation of degradation and remodelling of the extracellular matrix, which is one of the elements involved in the reconstruction of the structure of the bronchi in severe asthma. This paper presents the antagonistic properties of BMP against TGF- $\beta$, anti-inflammatory and counteracting fibrosis in the respiratory tract. The current state of knowledge indicates that this group of cytokines are potential new markers of remodelling in severe asthma, and further studies on their therapeutic value are necessary.
\end{abstract}

Key word: bone morphogenetic proteins, BMP signalling pathway, inflammation, remodelling, asthma

Adv. Respir. Med. 2017; 85: 109-115

\section{Introduction}

Asthma is a heterogeneous, chronic inflammatory disease typified by airway hyperresponsiveness and paroxysmal variable bronchial obstruction provoked by specific and non-specific factors [1]. The pathophysiological basis of asthma stems from three phenomena: airway hyperresponsiveness to specific and non-specific factors, variable and reversible airway obturation, and chronic inflammation of the bronchial mucosa.

The inflammation process involves inflammatory cells such as Antigen Presenting Cells (APC), T lymphocytes, mast cells, eosinophils, macrophages and neutrophils, as well as structural cells including epithelial cells, myocytes, fibroblasts and myofibroblasts, nerve cells and vascular endothelial cells [2]. One of the causes of airway hyperresponsiveness is epithelial damage
[3]. The CysLT1 receptor is activated with C4, D4 and E4 leukotrienes, secreted by mast cells, and this is followed by muscle spasms. Besides leukotrienes, mast cells also secrete a number of pro-inflammatory cytokines, prostaglandins and histamine, particularly following repetitive stimulation by allergens. Following the onset of the disease, the bronchial walls of the respiratory tract undergo an ongoing, highly-adverse process known as remodelling, which results in reduced elasticity, thickening of the muscular layer, increased angiogenesis and the deposition of an extracellular matrix (ECM) [4]. The activation of fibroblasts, and the differentiation and secretion of increased amounts of collagen is caused mainly by TGF- $\beta 1$.

Type- $\beta$ transforming growth factors (TGF- $\beta$ ) are pleiotropic compounds produced by most epithelial and fibroblastic cells. They share the

Address for correspondence: Marcelina Koćwin, Department of Internal Medicine, Asthma and Allergy, Medical University of Lodz, 22 Kopcinskiego St., 90-153, Lodz, Poland, e-mail: marcelina.kocwin@gmail.com

DOI: 10.5603/ARM.2017.0017

Received: 15.01.2017

Copyright (C) 2017 PTChP

ISSN 2451-4934 
action of cytokines, as well as of stimulators and inhibitors of growth and proliferation $[5,6]$. The subfamily of the TGF- $\beta$ superfamily includes Bone Morphogenetic Proteins (BMP), Growth Differentiation Factors (GDF) and Anti-Müllerian Hormone (AMH) [7].

Bone morphogenetic proteins regulate a number of developmental processes for both embryonic and post-embryonic organogenesis: they take part in bone formation, wound healing and immune response [8, 9]. BMP expression was first discovered in bones, but has also been found in other organs such as the bone primordia (BMP-2,4,5,7), kidneys (BMP-3,4,7), heart (BMP-2,4,6,7) and teeth (BMP-3,4,7). In addition, BMP subtypes 3, 4 and 7 have been observed in lung tissue [10-13]. Among the 20 known members of the BMP family, the strongest osteoinductive properties are demonstrated by isoforms BMP-2, 6 and 9, both in the bone tissue and heterotopic areas [14]. However, although BMP-3, 4 and 7 have less osteoinductive potential, they demonstrate regulatory activity in the development and differentiation of fibroblasts, which may take part in the remodelling of the respiratory tract $[15,16]$.

\section{The BMP-SMAD signalling pathway}

Cellular transduction of signalling by BMP occurs through the SMAD protein (mothers against decapentaplegic homolog), in a similar way to proteins from the TGF- $\beta$ family. Two types of BMP receptors are required to carry the signal: the serine-threonine kinases BMPR-I and BMPR-II (BMPR- bone morphogenetic protein receptor). BMPR-I comprises two receptor subtypes, BMPR-1A (ALK-3) and BMPR-1B (ALK-6), and activin receptor-like kinase-2 (ALK-2), binding activin and BMP-7, while BMPR-II includes BMPR-2, a type II activin receptor (ActRII) and type IIB activin receptor (ActRIIB) [17]. The signal can be passed into the cell nucleus via the canonical pathway (with the participation of SMAD), or a non-canonical pathway by MAP kinases (MAPKmitogen activated protein kinases), $\mathrm{N}$-terminal kinase (JNK), p38 kinase or Phosphoinositide-3-kinase (PIK3), RAS proteins.

The SMAD family of mediating proteins are derived from two homologous proteins: Sma, occurring in Caenorhabditis elegans, and Mad, present in Drosophila melanogaster. The SMAD family can be divided into three groups: proteins activated by the R-SMAD receptor, such as SMAD-1,2,3,5 or 8; Co-SMAD, i.e. co-mediating protein SMAD4 ; and the I-SMAD inhibitory proteins, represented by SMAD 6 and 7. SMAD 1, 5 and 8 are activated by BMP signalling. In canonical signalling, after merging, the complex formed by BMP and SMAD-1, 5 or 8 links to the common mediator Co-SMAD4, which allows transport to the cell nucleus [18]. In the cell nucleus, the R-SMAD/Co-SMAD complex binds to the promotors associated with the SRE sequence (SMAD-Response Elements) and following that binding, it regulates their transcription [19].

The genes responsible for mediating SMAD with BMP depend on the type of cell or tissue [20]. SMAD acts as a mediator in inflammation and fibrosis, as well as in epithelial-to-mesenchymal transition (EMT) induced by TGF- $\beta 1$ [21]. BMP-6 and BMP-7 activate only two of the three R-SMADs, i.e. SMAD1 and SMAD5, whereas BMP-2 activates all SMAD subtypes [22]. It is suggested that some proteins from the BMP family are able to deactivate parts of the SMAD1 and SMAD5 regulatory proteins [23]. BMPs, together with their BMPR-SMAD signal pathway, TGF- $\beta$ and TGF $\beta$ R-SMAD undergo mutual interactions. The co-mediating protein Co-SMAD 4 is the common link. When the intracellular level of SMAD4 is limited, ligands of the TGF $\beta$ R and BMPR receptors modulate its competing activity towards SMAD4 [24]. Correct BMP signalling is essential for the correct promotion and regulation of regeneration, repair and maintenance of tissues where BMP expression is found.

Due to the fact that BMPs belong to the TGF- $\beta$ superfamily, they have similar signal transduction mechanisms and common co-mediating protein and the confirmed expression of certain subtypes of BMP in the respiratory tract, which results in the need for further studies concerning the possible role of BMPs in the pathological mechanism of bronchial asthma development and subsequent remodelling. Besides, BMPs may be hypothetically used as biomarkers of disease progress in patients.

\section{The BMP protein and BMPR receptor: expression, function and role in the respiratory tract}

Although BMP-3 remains not fully understood, the BMP-3 gene is known to be present in chromosome 4q21.21 [26]. The BMP-3 molecule demonstrates high affinity to the activin receptor ActRII, but lower to ActRIIb. Next, the signal is carried to the cell nucleus using the SMAD protein [27]. Expression is located mainly in the neuroectodermis and the forming s periosteum, which suggests that BMP-3 may be engaged in 


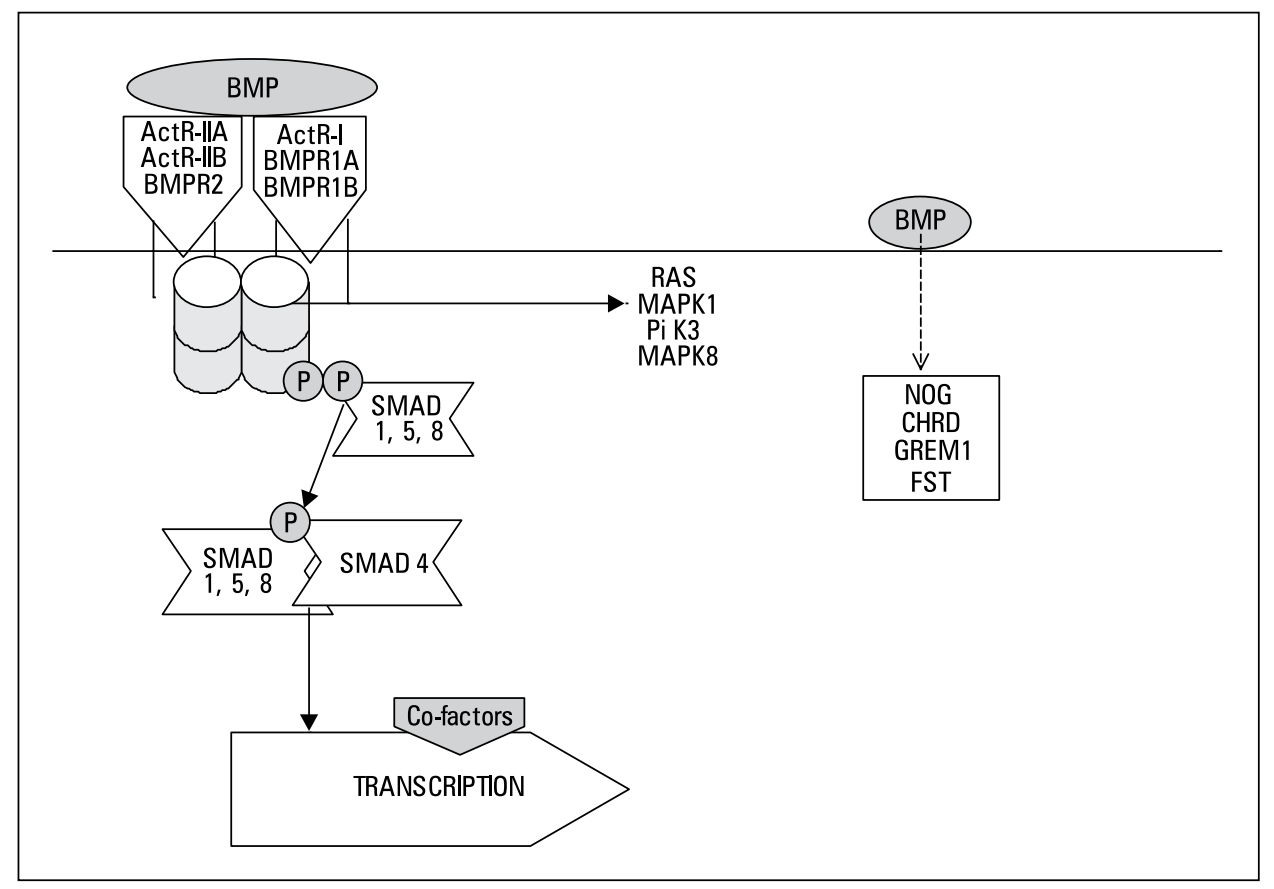

Figure 1. BMP signalling pathways based on [25], own modified. In canonical pathway of BMP signal is transduced through the heteromeric complex with BMP ligand and type I and type II BMP receptors. That complex after phosphorylation is binded with phosporylated SMAD 1, 5, 8 and then merged with co-mediating protein SMAD4, then this newly-formed complex is transported into the nucleus for initiating the transcription. In the non-canonical pathway signal may be transduced via MAPK1, PIK3, MAPK8, RAS. There are also several extracellular inhibitors for BMP, i.e. NOG, CHRD (chordin), GREM1 (Gremlin) and FST (follistatin) or by the receptor BAMBI

the early development of bones during embryogenesis [26]. Studies of six-week-old embryos have revealed the expression of BMP-3 mRNA in epithelial stem cells of the bronchial epithelium, and later in epithelial cells lining the buds of bronchial branches [11]. Some studies propose that BMP-3 may act as an inhibitor for other members of the BMP family. This hypothesis has been confirmed by tests on double knockout mice in which a significant increase in bone mass was observed; however, more frequent spontaneous fractures were observed in the case of mice with BMP-3 overexpression [28]. In a study of allergic rhinitis in a mouse model, a significant reduction in the expression of BMP-3 and BMP-5 was observed following exposure to the allergen Aspergillus fumigatus. In the same test, the expression of a range of cytokines from Fibroblast Growth Factors (FGF) and Matrix Metalloproteinases (MMP) was found to be elevated after exposure to a specific allergen. These findings suggest that signal transduction in cells intended for initiating the process of fibrogenesis and remodelling is initiated earlier in inflammatory illnesses [29].

BMP-4 is an important regulatory molecule, inducing mesoderm formation and tooth and limb growth during embryogenesis, and the later formation of bone tissue and healing of fractures [17].
The gene for BMP-4, mapped onto chromosome $14 \mathrm{q}-22.2$, has two promotor regions, which are subject to expression occurring in a cell type-specific manner. It is important to note that construction of BMP- 4 includes the propeptide TGF- $\beta 1$ domain and the TGF- $\beta$ domain to form an active dimer [30]. BMP-4 is an important signalling molecule for lung embryogenesis [13], with the epithelium of the distal tips of the terminal buds demonstrating greater BMP-4 mRNA expression than the adjoining mesenchyme. Tests on transgenic mice have revealed that BMP-4 misexpression, controlled by the enhancer sequences of the Surfactant Protein C (SP-C) promotor, leads to a reduction in lung size, hyperinflation of the bronchiole tips and impaired gas exchange after birth [15]. It has been postulated that BMP-4 may play a role in the local inhibition of bronchial epithelial cell proliferation, which would inhibit the signal modulating FGFs. This theory has been demonstrated by the presence of hypoplastic epithelial tissue production in studies of transgenic mice with BMP-4 misexpression, and in studies where the BMP-4 ligand was added to in vitro epithelial cultures lacking BMP-4 expression [31].

Jefferey et al. [32] also note that BMP-4 has an inhibitory effect on fibrogenesis. It was found that BMP-4 has both antiproliferative and pro- 
-differentiation effects on the lung epithelium. After examining the BMP-4 signalling pathway, using both the SMAD and mitogen-activated protein kinase (MAPK) pathways, it can be suggested that while the promotion of proliferation is dependent on the action of SMAD1 and c-Jun N-terminal kinase (JNK), the antiproliferative properties are dependent on SMAD1. As SMAD1 is the predominant signalling molecule engaged in the proliferation and differentiation of fibroblasts, it may inhibit the processes using BMP-4. Although the role of BMP-4 in the degradation of the ECM is not fully understood, BMP-4 is believed to be able to counter its growth and induce the proliferation of normal human lung fibroblasts (NHLF) using TGF- $\beta 1$ [33]. Most importantly, studies which have been recently conducted reveal that BMP-4 not only regulates the level of MMP-13 expression connected with fibroblasts, but also the expression of MMP-13 induced by TGF- $\beta 1$ $[16,34]$. However, although these studies do not confirm that BMP-4 has a direct influence on fibroblast proliferation, they do indicate that it has an indirect action, which encourages the search for new diagnostic and therapeutic applications. The possibility of the partial reversal or inhibition of remodelling translates into improvements in the quality of life of patients and prevents some of the effects of severe asthma.

BMP-7, also known as osteogenic protein 1 (OP1), is mapped on chromosome 20q13.31. BMP7 is expressed in the limb buds, heart, the retinal neuroepithelium, the lens and cornea, kidney and lung fibroblasts [35]. BMP-7 can bind to ALK-2, which activates the SMAD1 and SMAD5 transport proteins. SMAD1 carries the signal for initiating the formation and differentiation of fibroblasts. BMP-7 is known to have an affinity with ActRI, which may suggest that BMP-7 plays a role in these processes [36]. It is also noted that the absence of BMP-7 is associated with the preferential activation of the TGF- $\beta$ receptor, the phosphorylation and activation of SMAD2 and SMAD3, followed by their translocation to the nucleus to begin the translation of TGF- $\beta$ products [37].

BMP-7 plays a role in the differentiation of stem cells into osteoblasts and induction of osteogenesis [38], as well as in fibrogenesis and the differentiation of myofibroblasts [39]. It is important to note that BMP-7 has the potential to partially reverse fibrogenesis induced by TGF- $\beta 1$ in the kidneys, heart and colon [40, 41]. In addition, it is able to inhibit epithelium-to-mesenchymal transition (EMT), whose constant activation induces chronic inflammation and fibrosis of tissues and organs [42]. Mesenchymal tissues, fibroblasts and myofibroblasts are the primary cells producing the ECM during fibrogenesis. At this stage, BMP-7 is able to inhibit collagen type I (COL1A2) production induced by TGF- $\beta 1$. BMP-7 inhibits the expression of collagen type I mRNA, A-Smooth Muscle Actin (A-SMA) and Tissue Inhibitor of Metalloproteinase Protein-2 (TIMP) by the induction of Id2 (Inhibitor of Differentiation 2). BMP-7 and Id 2 reduce the secretion of collagen dependent on TGF- $\beta 1$ [43]. Transforming growth factor (TGF. Collagen types I and III, produced by the action of TGF- $\beta 1$, are the main components of the ECM involved in airway remodelling alongside laminins, elastins and fibronectins [44]. Therefore BMP-7 acts against remodelling by reducing the secretion of collagen.

For another antifibrotic mechanism, it is possible to look at the inhibition of the release of MMP-2 and MMP-13 metalloproteinases induced by TGF- $\beta 1$ [16]. MMP-13 is one of the main collagenases responsible for the degradation of collagen, while MMP-2 hydrolyses the peptide bonds in collagen types I, II and III [45]. In asthma, metalloproteinases are involved in angiogenesis, and hyperplasia of the smooth muscle cells of the bronchus resulting from activation by TGF- $\beta 1$; they also have an influence on inflammatory cell release and maintaining bronchial hyperresponsiveness [46]. Studies have demonstrated a constitutive lowering of BMP-7 levels in human mild asthma patients. After exposure to an allergen, a significant increase of protein expression was observed in the epithelium and in inflammatory cells [47]. This confirms that BMP-7 plays a role in EMT, but also suggests that it acts as a regulator in inflammation and tissue repair [48].

A similar increase of TGF- $\beta 1$ expression was observed in both acute and chronic conditions in tests on mice immunised with ovoalbumin; however, only the chronic group demonstrated a fast increase of BMP-7 expression, which correlated positively with higher levels of collagen deposition. The mice were then subjected to specific BMP-7 therapy, which was found to be effective at inhibiting collagen type I induced by TGF- $\beta 1$ [49]. The mouse studies offer promise for trials on the use of BMP proteins as markers of severe asthma associated with remodelling in humans.

The possibilities of clinical use of anti-fibrotic mechanism of BMP would be advantageous in patients with moderate and severe asthma. In patients with less advanced forms of asthma, the recombinant BMP proteins would be used 


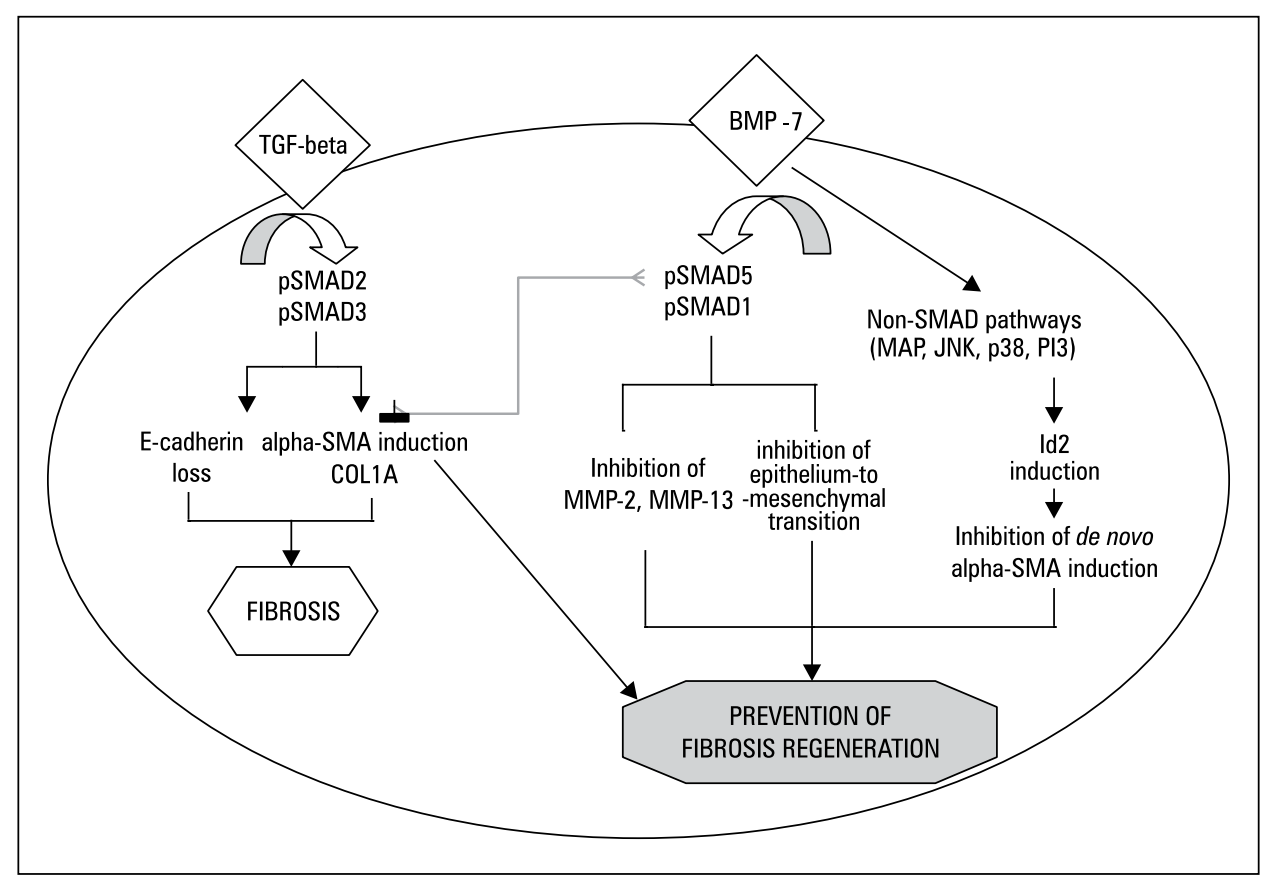

Figure 2. Potential regenerative and anti-fibrosis mechanism of BMP-7 based on [43], own modified template. BMP-7 inhibits the expression of collagen type I mRNA, A-Smooth Muscle Actin (A-SMA) and Tissue Inhibitor of Metalloproteinase Protein-2 (TIMP) by the induction of Id2. BMP-7 and Id2 reduce the secretion of collagen dependent on TGF- $\beta 1$. The inhibition of fibrosis by reducing collagen secretion and the release of matrix metalloproteinases as well as by the inhibition of epithelial-to-mesenchymal transition results in a decrease in intensity of inflammation in the tissues and partial reversion of fibrosis effects

as the causal treatment to prevent fibrosis and irreversible rebuilding. We believe that the prevention of the remodelling would keep the disease under control (evaluated by ACQ- asthma control questionnaire), prolong the patient's life and improve its quality (AQLQ- asthma quality of life questionnaire). The inhibition of fibrosis by reducing collagen secretion and the release of matrix metalloproteinases, as well as by the inhibition of epithelial-to-mesenchymal transition results in a decrease in intensity of inflammation in the tissues and partial reversion of fibrosis effects. Partial rebuilding of the tissues would be clinically manifested by lessening the obstruction, improving the spirometry results and better response to treatment. One of the reasons for the ineffectiveness of bronchodilators in severe asthma is irreversible obstruction. The use of the causal treatment of specific biological therapy and recombinant factor inhibiting inflammation and fibrosis in combination with conventional anti-inflammatory and bronchodilator therapy would probably improve the control over the disease and prevent its distant effects. For this reason, further study of bone morphogenetic proteins, especially BMP-4 and BMP-7 in terms of their ability to inhibit or reverse fibrosis appears to be justified.

It is important to note that in 2001, the FDA (Food and Drug Administration) opened clinical trials of the osteoinductive potential for recombined rh-BMP7 (Eptotermin-A), which actively recruits mesenchymal stem cells from the tissue surrounding the bones and initiates a cascade of bone formation [50]. Although rhBMP-7 has only been used to a limited degree, this result offers hope that other molecules of recombinant BMP-7 could be used in the prevention, control and treatment of the symptoms of severe asthma associated with remodelling.

Either overexpression or the lack of expression of any BMPR receptors results in disturbances in intracellular signalling along the BMPR-SMAD pathways. In illnesses with impaired BMPR-SMAD transduction like Primary Pulmonary Hypertension (PPH) or Non-Small Cell Lung Cancer (NSCLC), the lack of BMP-regulated signalling promotes the expression of other growth factors [51]. Patients with a mild course of asthma demonstrate lower constitutive expression of BMPR-I, BMPR-II, ALK-2 and ALK-6 receptors, compared to a control group. This suggests that the 'down-regulation' of signalling pathways in patients with mild disease may contribute to an increase in the activity of remodelling processes after the transition to symptomatic asthma. Following exposure to allergen, patients with mild asthma demonstrated restitution of the BMPR receptors and fast activation of the 
ligand-activated signalling pathway, which was maintained for the following seven days; this may be associated with the initiation of the cascade of anti-inflammatory and antifibrotic processes [47].

\section{Summary}

Studies have indicated the role played by subtypes of bone morphogenetic protein (BMP) in the pathogenesis of respiratory diseases accompanied by fibrosis. BMP signalling pathways are active in the respiratory tract and form an integral part of the physiological response to damage to the tissue and smooth muscle of the respiratory tract. The sources given in this study highlight the role of BMP-4 and BMP-7 in the degradation and remodelling of the extracellular matrix, which is one of the elements involved in the reconstruction of the structure of the bronchi in severe forms of asthma. The BMP-4 and BMP-7 subtypes exhibit antifibrotic effects which act antagonistically to TGF- $\beta 1$, the main cytokine increasing the risk of fibrogenesis.

The effects of BMP are numerous and varied: they modulate the activity of lung fibroblasts, myofibroblasts and elements of the extracellular matrix. Study results which have been obtained so far encourage to conduct in vivo and in vitro experiments with the use of animal models. Bronchial asthma has been found to be associated with dysregulation of BMP protein and BMPR receptor expression, and the constitutive level of these receptors and the changes in their expression may be used in diagnostics as predictive markers of severe asthma. In addition, disorders at this level can be targets for the creation of new small molecule ligands of the BMPR receptor with the use of molecular biology techniques. The antifibrotic activities of BMP represent a promising field for therapeutic intervention. The possibility of even a partial reversal of the effects of airway remodelling can significantly translate into control of asthma symptoms, reducing the chronic effects of the prolonged disease process, extending life expectancy and improving the quality of life. Further detailed studies of the expression and regulation of BMP proteins, their mechanisms of activation and intracellular signalling seem to be significant from the point of view of diagnostics, reflecting the development of the fields of biology and molecular biology, and the growth of gene therapy.

\section{Conflict of interest}

The authors declare no conflict of interest.

\section{References:}

1. Global Initiative for Asthma, http:/ginasthma.org/

2. Wong CK, Ho CY, Ko FW, et al. Proinflammatory cytokines (IL17, IL-6, IL-18 and IL-12) and Th cytokines (IFN-gamma, IL-4, IL-10 and IL-13) in patients with allergic asthma. Clin Exp Immunol. 2001; 125(2): 177-183, indexed in Pubmed: 11529906.

3. Krenke R. Astma oskrzelowa - aktualny stan wiedzy. Pulmonologia Med i Pasje. 2009; 2-11.

4. Hershenson MB, Brown M, Camoretti-Mercado B, et al. Airway smooth muscle in asthma. Annu Rev Pathol. 2008; 3: 523-555, doi: 10.1146/annurev.pathmechdis.1.110304.100213, indexed in Pubmed: 18039134.

5. Stępień-Wyrobiec O, Hrycek A, Wyrobiec G. Transformujący czynnik wzrostu beta (TGF-beta)-budowa, mechanizmy oddziaływania oraz jego rola w patogenezie tocznia rumieniowatego UKładowego. Postepy Hig Med Dosw. 2008; 62: 688-93.

6. Mokrosiński J, Krajewska WM. Receptory pomocnicze w sygnalizacji TGF $\beta$. Postepy Biochem. 2008; 54(3): 264-73.

7. Wu MY, Hill CS. Tgf-beta superfamily signaling in embryonic development and homeostasis. Dev Cell. 2009; 16(3): 329343, doi: 10.1016/j.devcel.2009.02.012, indexed in Pubmed: 19289080.

8. Wozney JM. The bone morphogenetic protein family and osteogenesis. Mol Reprod Dev. 1992; 32(2): 160-167, doi: $10.1002 /$ mrd.1080320212, indexed in Pubmed: 1637554.

9. Clark RI, Woodcock KJ, Geissmann F, et al. Multiple TGF- $\beta$ superfamily signals modulate the adult Drosophila immune response. Curr Biol. 2011; 21(19): 1672-1677, doi: 10.1016/j. cub.2011.08.048, indexed in Pubmed: 21962711.

10. Ahn K, Mishina Y, Hanks MC, et al. BMPR-IA signaling is required for the formation of the apical ectodermal ridge and dorsal-ventral patterning of the limb. Development. 2001; 128(22): 4449-4461, indexed in Pubmed: 11714671.

11. Vukicevic S, Helder MN, Luyten FP. Developing human lung and kidney are major sites for synthesis of bone morphogenetic protein-3 (osteogenin). J Histochem Cytochem. 1994; 42(7): 869-875, doi: 10.1177/42.7.8014470, indexed in Pubmed: 8014470 .

12. Bellusci S, Henderson R, Winnier G, et al. Evidence from normal expression and targeted misexpression that bone morphogenetic protein (Bmp-4) plays a role in mouse embryonic lung morphogenesis. Development. 1996; 122(6): 1693-1702, indexed in Pubmed: $\underline{8674409}$.

13. Wang RN, Green J, Wang Z, et al. Bone Morphogenetic Protein (BMP) signaling in development and human diseases. Genes Dis. 2014; 1(1): 87-105, doi: 10.1016/j.gendis.2014.07.005, indexed in Pubmed: 25401122.

14. Luu HH, Song WX, Luo X, et al. Distinct roles of bone morphogenetic proteins in osteogenic differentiation of mesenchymal stem cells. J Orthop Res. 2007; 25(5): 665-677, doi: 10.1002/ jor.20359, indexed in Pubmed: 17290432.

15. Warburton D, Schwarz M, Tefft D, et al. The molecular basis of lung morphogenesis. Mech Dev. 2000; 92(1): 55-81, indexed in Pubmed: 10704888.

16. Pegorier S, Campbell GA, Kay AB, et al. Bone morphogenetic protein (BMP)-4 and BMP-7 regulate differentially transforming growth factor (TGF)-beta1 in normal human lung fibroblasts (NHLF). Respir Res. 2010; 11: 85, doi: 10.1186/14659921-11-85, indexed in Pubmed: 20573231.

17. Chen Di, Zhao M, Mundy GR, et al. Signal transduction and biological functions of bone morphogenetic proteins. Front Biosci. 2004; 9(4): 349-358, indexed in Pubmed: 14766372.

18. Massagué J, Seoane J, Wotton D. Smad transcription factors. Genes Dev. 2005; 19(23): 2783-2810, doi: 10.1101/ gad.1350705, indexed in Pubmed: 16322555.

19. Gingery A, Bradley EW, Pederson L, et al. TGF-beta coordinately activates TAK1/MEK/AKT/NFkB and SMAD pathways 
to promote osteoclast survival. Exp Cell Res. 2008; 314(15): 2725-2738, doi: 10.1016/j.yexcr.2008.06.006, indexed in Pubmed: 18586026.

20. Yoshida Y, Tanaka S, Umemori H, et al. Negative regulation of BMP/Smad signaling by Tob in osteoblasts. Cell. 2000; 103(7): 1085-1097, indexed in Pubmed: 11163184.

21. Flanders K, Sato M, Ooshima A, Russo A, Roberts A. Smad-3 as a mediator of the fibrotic response. Int J Exp Pathol. 2008; 85(1): A13-A13.

22. Aoki H, Fujii M, Imamura T, et al. Synergistic effects of different bone morphogenetic protein type I receptors on alkaline phosphatase induction. J Cell Sci. 2001; 114(Pt 8): 1483-1489, indexed in Pubmed: 11282024.

23. Zwijsen An, Verschueren K, Huylebroeck D. New intracellular components of bone morphogenetic protein/Smad signaling cascades. FEBS Lett. 2003; 546(1): 133-139, indexed in Pubmed: 12829249.

24. Eivers E, Fuentealba LC, De Robertis EM. Integrating positional information at the level of Smad1/5/8. Curr Opin Genet Dev. 2008; 18(4): 304-310, doi: 10.1016/i.gde.2008.06.001, indexed in Pubmed: 18590818.

25. van Wijk B, Moorman AFM, van den Hoff MJB. Role of bone morphogenetic proteins in cardiac differentiation. Cardiovasc Res. 2007; 74(2): 244-255, doi: 10.1016/i.cardiores.2006.11.022, indexed in Pubmed: 17187766.

26. Allendorph GP, Isaacs MJ, Kawakami Y, et al. BMP-3 and BMP6 structures illuminate the nature of binding specificity with receptors. Biochemistry. 2007; 46(43): 12238-12247, doi: 10.1021/bi700907k, indexed in Pubmed: 17924656.

27. Gamer LW, Ho V, Cox K, et al. Expression and function of BMP3 during chick limb development. Dev Dyn. 2008; 237(6): 1691-1698, doi: 10.1002/dvdy.21561, indexed in Pubmed: 18489005.

28. Daluiski A, Engstrand T, Bahamonde ME, et al. Bone morphogenetic protein-3 is a negative regulator of bone density. Nat Genet. 2001; 27(1): 84-88, doi: 10.1038/83810, indexed in Pubmed: 11138004.

29. Sautter NB, Delaney KL, Trune DR. Altered expression of tissue remodeling genes in a mouse model of acute allergic rhinitis. Int Forum Allergy Rhinol. 2011; 1(4): 262-267, doi: 10.1002/alr.20059, indexed in Pubmed: 21894256.

30. http://omim.org/entry/112262?search=bone\%20morphogenetic $\% 20$ proteins\&highlight $=$ protein $\% 20$ morphogenetic $\% 20$ bone.

31. Warburton D, Bellusci S, De Langhe S, et al. Molecular mechanisms of early lung specification and branching morphogenesis. Pediatr Res. 2005; 57(5 Pt 2): 26R-37R, doi: 10.1203/01. PDR.0000159570.01327.ED, indexed in Pubmed: 15817505.

32. Hashimoto S, Gon Y, Takeshita I, et al. Transforming growth Factor-beta1 induces phenotypic modulation of human lung fibroblasts to myofibroblast through a c-Jun-NH2-terminal kinase-dependent pathway. Am J Respir Crit Care Med. 2001; 163(1): 152-157, doi: 10.1164/ajrccm.163.1.2005069, indexed in Pubmed: 11208641.

33. Jeffery TK, Upton PD, Trembath RC, et al. BMP4 inhibits proliferation and promotes myocyte differentiation of lung fibroblasts via Smad1 and JNK pathways. Am J Physiol Lung Cell Mol Physiol. 2005; 288(2): L370-L378, doi: 10.1152/ajplung.00242.2004, indexed in Pubmed: 15516492.

34. Otto TC, Bowers RR, Lane MD. BMP-4 treatment of C3H10T1/2 stem cells blocks expression of MMP-3 and MMP-13. Biochem Biophys Res Commun. 2007; 353(4): 1097-1104, doi: 10.1016/j.bbrc.2006.12.170, indexed in Pubmed: 17204246.
35. http://omim.org/entry/112267?search=bone\%20morphogenetic\%20protein \%207\&highlight=proteinaceous\%20protein\%20morphogenetic\%20bone\%207\#4.

36. Macías-Silva M, Hoodless PA, Tang SJ, et al. Specific activation of Smad1 signaling pathways by the BMP7 type I receptor, ALK2. J Biol Chem. 1998; 273(40): 25628-25636, indexed in Pubmed: $\underline{9748228}$.

37. Wang S, Hirschberg R. BMP7 antagonizes TGF-beta -dependent fibrogenesis in mesangial cells. Am J Physiol Renal Physiol. 2003; 284(5): F1006-F1013, doi: 10.1152/ajprenal.00382.2002, indexed in Pubmed: 12676736.

38. Cheng H, Jiang W, Phillips FM, et al. Osteogenic activity of the fourteen types of human bone morphogenetic proteins (BMPs). J Bone Joint Surg Am. 2003; 85-A(8): 1544-1552, indexed in Pubmed: 12925636.

39. You L, Kruse FE. Differential effect of activin A and BMP-7 on myofibroblast differentiation and the role of the Smad signaling pathway. Invest Ophthalmol Vis Sci. 2002; 43(1): 72-81, indexed in Pubmed: 11773015.

40. Klahr S, Morrissey J. Obstructive nephropathy and renal fibrosis: The role of bone morphogenic protein-7 and hepatocyte growth factor. Kidney Int Suppl. 2003(87): S105-S112, indexed in Pubmed: 14531782.

41. Maric I, Poljak L, Zoricic S, et al. Bone morphogenetic protein-7 reduces the severity of colon tissue damage and accelerates the healing of inflammatory bowel disease in rats. J Cell Physiol. 2003; 196(2): 258-264, doi: 10.1002/jcp.10275, indexed in Pubmed: 12811818.

42. Pieniążek M, Donizy P, Ziętek M. The role of TGF-b -related signal transduction pathways in pathogenesis of cancers. Postępy Hig Med Dośw. 2012; 66: 583-91.

43. Izumi N, Mizuguchi S, Inagaki Y, et al. BMP-7 opposes TGF -beta1-mediated collagen induction in mouse pulmonary myofibroblasts through Id2. Am J Physiol Lung Cell Mol Physiol. 2006; 290(1): L120-L126, doi: 10.1152/ajplung.00171.2005, indexed in Pubmed: 16126788.

44. Płusa T. The importance of small airways inflammation control in the course and therapy of bronchial asthma. Adv Dermatology Allergol Dermatologii i Alergol. 2009; XXVI(5): 354-356.

45. Lipka D, Boratyński J. Metaloproteinazy MMP. Struktura i funkcja. Postepy Hig Med Dosw. 2008; 62(5): 328-36.

46. Kraus-Filarska M, Kosińska M, Tomkowicz A. Metalloproteinases and Airway Remodeling in Asthma. Adv Clin Exp Med. 2007; 1(16): 417-423.

47. Kariyawasam HH, Xanthou G, Barkans J, et al. Basal expression of bone morphogenetic protein receptor is reduced in mild asthma. Am J Respir Crit Care Med. 2008; 177(10): 1074-1081, doi: 10.1164/rccm.200709-13760C, indexed in Pubmed: 18292470.

48. Zeisberg M, Hanai Ji, Sugimoto H, et al. BMP-7 counteracts TGF-beta1-induced epithelial-to-mesenchymal transition and reverses chronic renal injury. Nat Med. 2003; 9(7): 964-968, doi: 10.1038/nm888, indexed in Pubmed: 12808448.

49. Stumm CL, Halcsik E, Landgraf RG, et al. Lung remodeling in a mouse model of asthma involves a balance between TGF- $\beta 1$ and BMP-7. PLoS One. 2014; 9(4): e95959, doi: 10.1371/journal.pone.0095959, indexed in Pubmed: 24781156 .

50. Carreira AC, Lojudice FH, Halcsik E, et al. Bone morphogenetic proteins: facts, challenges, and future perspectives. J Dent Res. 2014; 93(4): 335-345, doi: 10.1177/0022034513518561, indexed in Pubmed: 24389809.

51. Kraunz KS, Nelson HH, Liu M, et al. Interaction between the bone morphogenetic proteins and Ras/MAP-kinase signalling pathways in lung cancer. Br J Cancer. 2005; 93(8): 949-952, doi: 10.1038/sj.bjc.6602790, indexed in Pubmed: 16175182. 